\title{
O gênero Apenesia (Hymenoptera, Bethylidae) na Mata Atlântica: notas e descrição de sete espécies novas
}

\author{
Michelle S. Corrêa ${ }^{1,2} \&$ Celso O. Azevedo ${ }^{1,3}$
}

\begin{abstract}
${ }^{1}$ Departamento de Biologia, Universidade Federal do Espírito Santo, Av. Marechal Campos 1468, 29.040-090 Vitória-ES, Brasil. ${ }^{2}$ Bolsista FACITEC/PMV. michelle.correa@gmail.com

${ }^{3}$ Pesquisador do CNPq. bethylidae@gmail.com
\end{abstract}

\begin{abstract}
The genus Apenesia (Hymenoptera, Bethylidae) in the Atlantic rain forest: notes and description of seven new species. Species of Apenesia Westwood, from 29 sites along a latitudinal gradient in the Atlantic rain forest were studied. The following seven new species were described and illustrated: Apenesia pectinata sp. nov., A. atlantica sp. nov., A. perlonga sp. nov., A. exigua sp. nov., A. patens sp. nov., A. simplex sp. nov. and A. hepatica sp. nov. The female of A. elongata Evans was discovered and described. New distribution records are provided for fourteen previously described species: A. apicilata Azevedo \& Batista, A. aurita Waichert \& Azevedo, A. clypeata Leal \& Azevedo, A. concavata Corrêa \& Azevedo, A. crenutala (Kieffer), A. distincta Corrêa \& Azevedo, A. elongata Evans, A. inca Evans, A. neotropica (Kieffer), A. photophila (Ogloblin), A. quadrata Evans, A. spinipes Evans, A. stricta Corrêa \& Azevedo and A. transversa Evans. Apenesia is recorded for the first time from the states of Paraíba, Pernambuco, Alagoas, Sergipe and Bahia.
\end{abstract}

KEYWORDS. Brazil; Morphology; Taxonomy.

RESUMO. O gênero Apenesia (Hymenoptera, Bethylidae) na Mata Atlântica: notas e descrição de sete espécies novas. Foram estudadas as espécies de Apenesia Westwood, coletadas em 29 localidades ao longo de um gradiente latitudinal na Mata Atlântica. Foram descritas e ilustradas as sete espécies novas seguintes: Apenesia pectinata sp. nov., A. atlantica sp. nov., A. perlonga sp. nov., A. exigua sp. nov., A. patens sp. nov., A. simplex sp. nov., A. hepatica sp. nov.. Foi descoberta e descrita a fêmea de Apenesia elongata Evans, 1963. Foram adicionados registros novos de distribuição geográfica de quatorze espécies previamente descritas: A. apicilata Azevedo \& Batista, A. aurita Waichert \& Azevedo, A. clypeata Leal \& Azevedo, A. concavata Corrêa \& Azevedo, A. crenutala (Kieffer), A. distincta Corrêa \& Azevedo, A. elongata Evans, A. inca Evans, A. neotropica (Kieffer), A. photophila (Ogloblin), A. quadrata Evans, A. spinipes Evans, A. stricta Corrêa \& Azevedo e A. transversa Evans. Apenesia é registrada pela primeira vez para os estados de Paraíba, Pernambuco, Alagoas, Sergipe e Bahia.

PALAVRAS-CHAVE. Brasil; Morfologia; Taxonomia.

O gênero Apenesia foi descrito por Westwood (1874) a partir da espécie A. amazonica, com base em apenas uma fêmea coletada na Amazônia. Evans (1963) acreditava que os gêneros Propristocera Kieffer, 1905, Cleistepyris Kieffer, 1910 e Dipristocera Kieffer, 1914, estavam intimamente associados à Apenesia, os quais foram sinonimizados. Revisou as espécies americanas do gênero, tendo incluído a descrição de 38 espécies novas, propôs uma chave de identificação, e organizou o gênero em grupos de espécies. Além disto, incluiu os gêneros Aeluroides Tullgren, 1904, Misepyris Fouts, 1930 e Neopristocera Benoit, 1957, como sinonímias do gênero. Existem 171 espécies de Apenesia descritas no mundo, sendo 96 delas da região Neotropical e 52 do Brasil. Mais recentemente Corrêa \& Azevedo (2001), Leal \& Azevedo (2001) e Waichert \& Azevedo (2003) estudaram o gênero em alguns remanescentes da Mata Atlântica, aumentando de 15 para 28 o número de espécies ocorrentes neste bioma.

O gênero Apenesia contém aquelas espécies de Pristocerinae cujo dígito da genitália masculina possui um processo em sua margem ventral próximo a sua inserção junto a basivolsela, o ramo ventral. Suas fêmeas são prontamente diferenciáveis por possuírem mesopleura pouco desenvolvida e porção anterior do disco propodeal constrita.

O dimorfismo sexual em Apenesia é muito pronunciado, assim como nos demais gêneros de Pristocerinae. Os machos são alados, de coloração geralmente escura, olhos e ocelos conspícuos e corpo com esculturação evidente, enquanto que as fêmeas são ápteras, de coloração pálida, olhos reduzidos a poucos omatídeos e corpo pouco esculturado. O menor número de caracteres taxonômicos em relação aos machos, associado ao fato de serem as fêmeas dificilmente amostradas com os métodos usualmente empregados, faz com que a taxonomia do grupo seja baseada quase que exclusivamente nos machos.

\section{MATERIALE MÉTODOS}

Foram amostradas localidades ao longo de um gradiente latitudinal da Mata Atlântica, resultantes, em sua maioria, de três projetos, "Riqueza de Hymenoptera e Isoptera ao longo de um gradiente latitudinal da Mata Atlântica Brasileira" apoiado pelo programa Biota/FAPESP, utilizando-se varredura de vegetação, armadilha Malaise e armadilha Möricke como 
métodos de coleta; "Biodiversidade de um Trecho de Mata Atlântica de Vitória: Bases para Estruturação de uma Coleção de Insetos com Vistas a Implementação de um Museu de História Natural no Município" apoiado pelo FACITEC, utilizando-se varredura de vegetação como método de coleta; e "Biodiversidade da Mata Atlântica do Espírito Santo" apoiado pelo $\mathrm{CNPq}$, utilizando-se armadilha Malaise como método de coleta. O material estudado foi depositado nas coleções de insetos da Universidade Federal do Espírito Santo (UFES) e do Museu de Zoologia da Universidade de São Paulo (MZSP). Os exemplares de algumas espécies foram comparados com material tipo de UFES, CASC - California Academy of Sciences, USA (R. Zuparko \& W. Pulawsky) e FIML Fundación y Instituto Miguel Lillo, Argentina (M.V. Colomo).

Os termos utilizados neste estudo seguem Evans (1963). As medidas utilizadas foram: comprimento da cabeça (LH); largura da cabeça (WH); largura da fronte (WF); comprimento do olho (HE); linha ocelar-ocular (OOL); largura do triângulo ocelar (WOT); diâmetro do ocelo anterior (DAO); distância do triângulo ocelar ao vértice; distância dos olhos à crista do vértice; comprimento e largura do disco propodeal; comprimento da asa anterior (LFW). A denominação dos tipos de escultura do integumento segue Harris (1979).

Foi adotada a classificação de grupos de espécies proposta por Evans (1963).

\section{RESULTADOS EDISCUSSÃO}

Foram encontrados exemplares de Apenesia nas 29 localidades de Mata Atlântica estudadas, totalizando 21 espécies, resultantes do somatório de sete espécies novas, nove espécies reincidentes e cinco espécies encontradas pela primeira vez neste bioma. Além disto, foi descoberta a fêmea de Apenesia elongata Evans, 1963. Como resultado deste trabalho houve também um aumento de 28 para 40 no número das espécies conhecidas para a Mata Atlântica, além da primeira citação do gênero para os estados da Paraíba, Pernambuco, Alagoas, Sergipe e Bahia.

\section{grupo de espécies brasiliensis}

Evans (1963) definiu o grupo brasiliensis como aquelas espécies que possuem metassomo com pecíolo curto e edeado complexo; e aquelas que, anteriormente, pertenceriam aos gêneros Cleistepyris e Dipristocera.

\section{Apenesia spinipes Evans, 1969}

Esta espécie era conhecida para a Argentina (Tucumán) e agora é citada pela primeira vez para o Brasil (Alagoas). Este material foi comparado com o holótipo e um parátipo, ambos de Tucumán, El Solidad, Argentina (FIML). Apesar da distância grande entre as duas localidades não foram encontradas variações taxonômicas entre os espécimes.

Material examinado. Brasil, 1 macho, Alagoas, Quebrangulo, Reserva Biol. Pedra Talhada, 09¹4'54"S 36²5’32"W, 11.XI.2002, varredura, A.M. Penteado-Dias e eq. col. (MZSP).

\section{Apenesia stricta Corrêa \& Azevedo, 2001}

Esta espécie foi descrita para a Reserva Biológica de Duas Bocas (Brasil, Espírito Santo), aqui os dados são ampliados para o Estado.

Material examinado. Brasil, 2 machos, Espírito Santo, Sooretama, Reserva Biológica de Sooretama, $19^{\circ} 00^{\prime} 11,5^{\prime \prime S} 40^{\circ} 07^{\prime} 08^{\prime \prime} \mathrm{W}$, 22.III.2002, varredura, C.O. Azevedo e eq. col. (MZSP, UFES).

\section{Apenesia transversa Evans, 1963}

Esta espécie era conhecida para o Espírito Santo, Rio de Janeiro, Paraná e Santa Catarina. Esta é a primeira citação para Bahia e São Paulo. Nesta série, foram encontradas as seguintes variações em relação aos espécimes da série-tipo: antenas e pernas mais claras; cabeça mais pontuada; estriações do disco propodeal bem desenvolvidas; ápice do parâmero pode ser mais estreito, margem superior mais côncava ou margem inferior arredondada; cúspides menores, chegando à metade da altura do parâmero.

Material examinado. BRASIL, Bahia, 2 machos, Ilhéus, Mata Esperança, $14^{\circ} 46^{\prime}$ 'S $39^{\circ} 04^{\prime} \mathrm{W}, 15-21 . V .2002$, armadilha Malaise, A.M. Penteado-Dias e eq. col. (MZSP); Porto Seguro, Estação Ecol. Pau Brasil, $16^{\circ} 23^{\prime} 17,6^{\prime \prime} \mathrm{S} 39^{\circ} 10^{\prime} 55^{\prime \prime} \mathrm{W}, 17 . \mathrm{V} .2002,1$ macho, armadilha Malaise, 1 macho, varredura, C.O. Azevedo e eq. col. (MZSP); Espírito Santo, Sooretama, Reserva Biol. Sooretama, $19^{\circ} 00^{\prime} 11,5^{\prime \prime} \mathrm{S} 40^{\circ} 07^{\prime} 08^{\prime \prime} \mathrm{W}$, 21.III-24.XI.2002, 1 macho, varredura, 2 machos, armadilha Malaise, C.O. Azevedo e eq. col. (MZSP); Pancas, Fazenda Juliberto Stur, 24.I07.II.2003, 4 machos, $19^{\circ} 12^{\prime} 54,8^{\prime \prime} \mathrm{S} 40^{\circ} 47^{\prime} 52,5^{\prime \prime} \mathrm{W}, 3$ machos, $19^{\circ} 13^{\prime} 10,5^{\prime \prime} \mathrm{S} 40^{\circ} 46^{\prime} 26,8^{\prime \prime} \mathrm{W}$, armadilha Malaise, M.T. Tavares, C.O. Azevedo e eq. col. (UFES); Santa Teresa, Estação Biol. Sta. Lucia, $19^{\circ} 58^{\prime} \mathrm{S} 40^{\circ} 32^{\prime} \mathrm{W}, 06-12 . \mathrm{IV} .2001,11$ machos, armadilha Malaise, 1 machos, varredura, 1 macho, $19^{\circ} 58^{\prime} \mathrm{S} 40^{\circ} 31^{\prime} \mathrm{W}$, 08.IV.2001, varredura, C.O. Azevedo e eq. col. (MZSP); Santa Maria de Jetibá, 2 machos, Fazenda Paulo Seick, 2002'31,1"S 4041'51,3"W, 06-13.XII.2002, armadilha Malaise, M.T. Tavares, C.O. Azevedo e eq. col. (UFES); 1 macho, Fazenda Clarindo Kruguer, 2004'27.9"S 4044'51,3"W, 29.XI06.XII.2002, armadilha Malaise, MT Tavares, C.O. Azevedo e eq. col. (UFES); Cariacica, 1 macho, Res. Biol. Duas Bocas, 31.VIII.2002, armadilha Malaise, Tavares col. (UFES); 5 machos, Vitória, Parque Est. Fonte Grande, $20^{\circ} 17^{\prime} 51,7^{\prime \prime S} 40^{\circ} 20^{\prime} 13,1$ "W, 09.IX.200026.XI.2001, varredura, Azevedo, Kawada e Santos col. (UFES); 2 machos, Domingos Martins, Parque Est. Pedra Azul, 20²5'55"S $41^{\circ} 00^{\prime} 53^{\prime \prime W}, 26$.VII-02.IX.2003, armadilha Malaise, C.O. Azevedo e eq. col. (UFES); 10 machos, Castelo, Pq. Est. Forno Grande, 1315.X.2000, varredura, Azevedo \& Santos col. (UFES); 1 macho, Alegre, Pq. E. Cachoeira da Fumaça, 11-12.X.2000, varredura, Azevedo \& Santos col. (UFES); Rio de Janeiro, Santa Maria Madalena, Parque Est. do Desengano, 21 ${ }^{\circ} 59^{\prime} 03^{\prime \prime S} 41^{\circ} 57^{\prime} 08^{\prime \prime} \mathrm{W}, 16-20 . I V .2002,3$ machos, armadilha Malaise, 3 machos, varredura, 1 macho, armadilha Möricke, A.M. Penteado-Dias e eq. col. (MZSP); Nova Iguaçu, Reserva Biol. do Tinguá, $22^{\circ} 34^{\prime} \mathrm{S} 43^{\circ} 26^{\prime} \mathrm{W}, 5-8 . \mathrm{III} .2002$, 1 macho, varredura, 1 macho, armadilha Malaise, S.T.P. Amarante e eq. col. (MZSP); São Paulo, 2 machos, Ubatuba, Parque Est. da Serra do Mar, núcleo Picinguaba, $23^{\circ} 21^{\prime} 43^{\prime \prime S} 44^{\circ} 49^{\prime} 22^{\prime \prime} \mathrm{W}, 21-24 . I .2002$, armadilha Malaise, N.W. Perioto e eq. col. (MZSP); Peruíbe, Estação Ecol. Juréia-Itatins, 243 $31^{\prime} 06^{\prime \prime S} 47^{\circ} 12^{\prime} 06^{\prime \prime W}$, 30.IV-5.V.2002, 3 machos, varredura, 1 macho, armadilha Malaise, N.W. Perioto e eq. col. (MZSP); Paraná, 2 machos, Morretes, Parque Est. do Pau Oco, 25³4’27,5"S 4853’33"W, 07-13.IV.2002, armadilha Malaise, M.T. Tavares e eq. col. (MZSP); Santa Catarina, 3 machos, São Francisco do Sul, CEPA-Vila da Glória, $26^{\circ} 13^{\prime} 40^{\prime \prime S} 48^{\circ} 40^{\prime} 49,1$ "W, 17-20.X.2001, armadilha Malaise, A.M. Penteado-Dias e eq. col. (MZSP); 3 machos, São Bento do Sul, CEPARugendas, $26^{\circ} 19^{\prime} 25,6^{\prime \prime} \mathrm{S} 49^{\circ} 18^{\prime} 26,5^{\prime \prime} \mathrm{W}, 13-16 . X .2001$, armadilha Möricke, A.M. Penteado-Dias e eq. col. (MZSP). 


\section{Apenesia pectinata sp. nov.}

(Figs. 1-3)

Diagnose. Preto. Mandíbulas com quatro dentes. Clípeo com lobo mediano arredondado. Fronte fracamente coriácea. Vértice ligeiramente arredondado. Disco pronotal com carena transversal anterior. Metassomo com pecíolo curto. Genitália com parâmeros subquadrados; ramo ventral do dígito muito grande, quase tão longo quanto o parâmero; edeago uniformemente largo, com dois pares de lobos ventrais, estreitos e curtos, e um par dorsal baixo e arredondado.

Descrição, macho: comprimento 5,57 mm; LFW 3,18 mm. Cabeça e mesossomo pretos; metassomo castanho-escuro; mandíbulas castanhas; antenas, palpos, tégulas e pernas castanho-claros; asas hialinas.

Cabeça (Fig. 1): mandíbula com quatro dentes, o inferior maior, o superior reduzido e arredondado (Fig. 2). Clípeo com lobo mediano arredondado, com um dente mediano voltado para baixo; com carena mediana elevada. Primeiros quatro segmentos antenais na razão de 20:5:11:12, segmento III 2,2x mais longo que largo, segmento XI 3,33x mais longo que largo, pubescência flagelar subapressa, seu comprimento um terço da largura do segmento. Olhos pilosos. Fronte fracamente coriácea, com pontuações pequenas e esparsas. WH/LH 1,01; WF/WH 0,62; WF/HE 1,18; OOL/WOT 1,9; ângulo frontal do triângulo ocelar agudo; distância do topo do ocelo posterior à crista do vértice $1,22 \times$ DAO. Vértice ligeiramente arredondado. VOL/HE0,56.

Mesossomo (Fig. 1): pronoto polido, piloso; carena transversal anterior presente; notáulices fracas anteriormente. Disco propodeal 1,47x mais largo que longo, carena mediana completa, carena transversal posterior inconspícua, lados do propódeo e declividade finamente estrigulosos. Mesopleura coriácea, calo desenvolvido. Tíbia mediana subespinhosa.

Metassomo: com pecíolo curto. Genitália (Fig. 3): parâmeros com base curta, cerca de um quarto do seu comprimento, muito estreita, ápice subquadrado, cantos arredondados, margem apical côncava, margem interna reta; volsela com ramo ventral do dígito muito grande, quase tão longo quanto o parâmero, piloso ventralmente, ápice dilatado; basivolsela fracamente pilosa; edeago uniformemente largo, menor do que a metade da altura do ápice do parâmero, com dois pares de lobos ventrais estreitos e curtos, com um par dorsal baixo e arredondado.

Material examinado. Holótipo macho, Brasil, Espírito Santo, Sooretama, Reserva Biol. Sooretama, $19^{\circ} 00^{\prime} 11,5^{\prime \prime S} 40^{\circ} 10^{\prime} 55^{\prime \prime} \mathrm{W}$, 22.III.2002, varredura, C.O. Azevedo e eq. col. (MZSP). Parátipos: BRASIL, 1 macho, Bahia, Porto Seguro, Estação Ecol. Pau Brasil, $16^{\circ} 23^{\prime} 17,6^{\prime \prime S} 39^{\circ} 10^{\prime} 55^{\prime \prime} \mathrm{W}, 17 . \mathrm{V} .2002$, armadilha Malaise, C.O. Azevedo e eq. col. (MZSP); 3 machos, Espírito Santo, mesmos dados do holótipo (MZSP, UFES).

Observações. Esta espécie é semelhante à A. spatulata Evans, 1969, da Argentina, de quem difere por apresentar o metassomo mais escuro, ápice do parâmero pouco côncavo, com cantos amplamente arredondados, basivolsela com margem basal convexa, dígito angulado e menor comprimento. Etimologia. Refere-se ao formato de pente do ramo ventral do dígito.

Distribuição. Brasil (Bahia, Espírito Santo).

\section{Apenesia atlantica sp. nov. \\ (Figs. 4-6)}

Diagnose. Preto. Mandíbulas com cinco dentes. Clípeo com lobo mediano truncado. Fronte polida. Vértice ligeiramente arredondado. Disco pronotal com carena transversal anterior. Metassomo com pecíolo curto. Genitália com parâmero subretangular; ramo ventral do dígito dilatado, arredondado, tão alto quanto a margem basal do ápice do parâmero; edeago uniformemente largo, com dois pares de lobos apicais, os medianos finos e longos, os laterais arredondados em vista lateral.

Descrição, macho: comprimento 6,55 mm; LFW 4,22 mm. Cabeça e mesossomo pretos; metassomo castanho-escuro; antena castanha; mandíbula, palpos, tégulas e pernas castanho-claros, exceto dentes, tíbias e fêmures mais escuros; asas subhialinas.

Cabeça (Fig. 4): mandíbula com cinco dentes, o inferior maior (Fig. 5). Clípeo com lobo mediano truncado, com os cantos arredondados; carena mediana pouco evidente. Primeiros quatro segmentos antenais na razão de 20:7:13:13, segmento III 2,6x mais longo que largo, segmento XI 3x mais longo que largo, pubescência flagelar subereta, seu comprimento um terço da largura do segmento. Olhos fracamente pilosos. Fronte polida, pontuação densa, pequenas e rasas. WH/LH 1,12; WF/WH 0,62; WF/HE 1,21; OOL/WOT 1,12; ângulo frontal do triângulo ocelar agudo; distância do topo do ocelo posterior à crista do vértice $1 \mathrm{x}$ DAO. Vértice ligeiramente arredondado; carena occipital visível em vista dorsal. VOL/HE 0,61 .

Mesossomo (Fig. 4): pronoto polido; carena transversal anterior presente; notáulices completas. Disco propodeal 1,36x mais largo que longo, carena mediana completa, carena transversal posterior indefinida, área posterior polida, lados do propódeo polidos no centro, fracamente coriáceo atrás, declividade estrigulosa. Mesopleura polida, calo bem desenvolvido.

Metassomo: peciolado, pecíolo curto. Genitália (Fig. 6): parâmero com base estreita, cerca da metade do comprimento do parâmero, ápice subretangular, inclinado, cantos arredondados, margem apical côncava, margem interna amplamente arredondada; volsela com ramo ventral do dígito piloso, ápice grande e dilatado, amplamente arredondado, base estreita, tão alta quanto a margem basal do ápice do parâmero; basivolsela fracamente pilosa; edeago uniformemente largo, mais longo do que a margem basal do ápice do parâmero, dois pares de lobos apicais, os medianos finos e longos, os laterais arredondados em vista lateral.

Material examinado. Holótipo macho, Brasil, Rio de Janeiro, Santa Maria Madalena, Parque Est. de Desengano, 2159'03"S 4157'08"W, 
16-19.IV.2002, armadilha Malaise, A.M. Penteado-Dias e eq. col. (MZSP). Parátipos: BRASIL, Espírito Santo, Santa Teresa, Estação Biol. Sta. Lucia, 1958'S 40³2'W, 06-12.IV.2001, 7 machos, varredura, 2 machos, armadilha Malaise, 1 macho, armadilha Möricke,

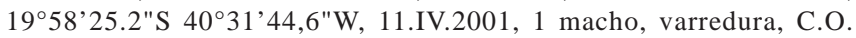
Azevedo e eq. col. (MZSP, UFES); 5 machos, Rio de Janeiro, mesmos dados do holótipo, exceto 16-22.IV.2002, armadilha Möricke (MZSP, UFES).

Observações. Esta espécie difere de A. venezuelana Evans, 1963, da Venezuela, por apresentar o parâmero com margem apical mais escavada e menos pilosa e ápice do edeago não tão dilatado.

Etimologia. É uma alusão à Mata Atlântica.

Distribuição. Brasil (Espírito Santo, Rio de Janeiro).

\section{grupo de espécies columbana}

O grupo columbana foi definido por Evans (1963) como aquelas espécies que possuem pubescência flagelar ereta e eriçada; pronoto com lados convexos; margem interna da volsela simples ou fracamente produzida, ou apresentando um processo digitiforme; e edeago com o ápice inclinado ventralmente.

\section{Apenesia apicilata Azevedo \& Batista, 2002}

Esta espécie foi descrita originalmente para o Parque Nacional da Serra do Divisor (Brasil, Acre), agora é citada pela primeira vez para o estado de Pernambuco. O único exemplar encontrado apresenta como variação em relação aos espécimes da série tipo as notáulices incompletas anteriormente. Este material foi comparado com dois parátipos, do Acre, Parque Nacional da Serra do Divisor, Brasil (UFES).

Material examinado. BRASIL, 1 macho, Paraíba, João Pessoa, Mata do Buraquinho, $07^{\circ} 08^{\prime} 25^{\prime \prime} \mathrm{S} 34^{\circ} 51^{\prime} 38^{\prime \prime} \mathrm{W}, 30$.VII.2002, varredura, S.P.T. Amarante e eq. col. (MZSP).

\section{Apenesia photophila (Ogloblin, 1930)}

Esta espécie era conhecida a partir de um único exemplar de Missiones, Argentina, região coberta por floresta ombrófila densa. Atualmente este holótipo está perdido, porém Ogloblin (1930) fez uma descrição detalhada acompanhada de uma série grande de ilustrações, o que permitiu o seu reconhecimento. Esta é a primeira citação da espécie para o Brasil (Bahia, Espírito Santo, Rio de Janeiro, São Paulo, Paraná e Santa Catarina). Nas descrições anteriores de Ogloblin (1930) e Evans (1963) nunca foi citada a presença de uma abertura na base do parâmero formando uma bolsa, uma característica ímpar. Nesta série, foram encontradas variações da descrição original como lobo mediano do clípeo com carena mediana não tão arqueada e mandíbula com cinco dentes, ao invés dos quatro descritos para o holótipo.

Material examinado. BRASIL, 1 macho, Bahia, Porto Seguro, Estação Ecol. Pau Brasil, 16²3'17,6"S 39¹0'55"W, 17.V.2002, armadilha Malaise, C.O. Azevedo e eq. col. (MZSP); Espírito Santo, 1 macho, Pancas, Fazenda Juliberto Stur, $19^{\circ} 12^{\prime} 54,8^{\prime \prime} \mathrm{S} 40^{\circ} 47^{\prime} 52,5^{\prime \prime W}$,
24-31.I.2003, armadilha Malaise, MT Tavares, C.O. Azevedo e eq. col. (UFES); 2 machos, Vitória, Parque Est. Fonte Grande, 20¹7'51,7"S $40^{\circ} 20^{\prime} 13,1$ "W, 4.I-22.II.2001, varredura, Azevedo, Kawada e Santos col. (UFES); 1 macho, Rio de Janeiro, Nova Iguaçu, Reserva Biol. do

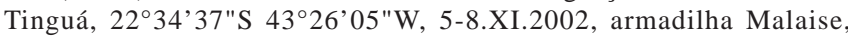
S.T.P. Amarante e eq. col. (MZSP); São Paulo, Salesópolis, Estação Biol. Boracéia, $23^{\circ} 39^{\prime} 06,5^{\prime \prime S} 45^{\circ} 53^{\prime} 48^{\prime \prime} \mathrm{W}, 30 . X I-4 . I V .2001,12$ machos, armadilha Malaise, 2 machos, varredura, S.T.P. Amarante e eq. col. (MZSP, UFES); Paraná, Morretes, Parque Est. do Pau Oco, $25^{\circ} 34^{\prime} 27,5^{\prime \prime S} 48^{\circ} 53^{\prime} 33^{\prime \prime} \mathrm{W}, 07-14 . I V .2002,3$ machos, armadilha Malaise, 1 macho, armadilha Möricke, M.T. Tavares e eq. col. (MZSP, UFES); 1 macho, Santa Catarina, São Bento do Sul, CEPA-Rugendas, 26²' $25,6^{\prime \prime} \mathrm{S} 49^{\circ} 18^{\prime} 26,5^{\prime \prime} \mathrm{W}, 16-19$. X.2001, armadilha Malaise, Penteado-Dias e eq. col. (MZSP).

\section{grupo de espécies laevigata}

O grupo laevigata foi definido por Evans (1963) como aquelas espécies com corpo pequeno e delgado, com ocelo é ligeiramente aumentado, disco propodeal margeado atrás somente nos lados e pecíolo do metassomo relativamente longo. Este grupo é relativamente próximo ao grupo exilis, entretanto há pouca semelhança entre a genitália dos dois grupos.

\section{Apenesia aurita Waichert \& Azevedo, 2002}

Esta espécie foi descrita originalmente para a Reserva Ecológica de Santa Lúcia (Brasil, Espírito Santo). Neste estudo, foram ampliados os dados de distribuição para o Espírito Santo, no município de Sooretama e Santa Maria de Jetibá, e é citada pela primeira vez para a Paraíba, Pernambuco e Bahia. Nesta série, os exemplares de Sooretama apresentam a coloração da antena e metassomo mais clara.

Material examinado. BRASIL, 3 machos, Paraíba, João Pessoa, Mata do Buraquinho, $07^{\circ} 08^{\prime} 25^{\prime \prime S} 34^{\circ} 51^{\prime} 38^{\prime \prime} \mathrm{W}$, armadilha Malaise, 25-31.VII.2002, S.P.T. Amarante \& eq. col. (MZSP, UFES); 1 macho, Pernambuco, Recife, Parque dos Dois Irmãos, 08 00’37,7"S $34^{\circ} 56^{\prime} 31^{\prime \prime W}$, armadilha Malaise, 17-20.VII.2002, S.P.T. Amarante \& eq. col. (MZSP); 1 macho, Bahia, Porto Seguro, Estação Ecol. Pau Brasil, 16²3'17,6"S 39¹0'55"W, 16.V.2002, varredura, C.O. Azevedo e eq. col. (MZSP); Espírito Santo, Sooretama, Reserva Biol. Sooretama, $19^{\circ} 00^{\prime} 11,5^{\prime \prime S} 40^{\circ} 07^{\prime} 08^{\prime \prime} \mathrm{W}, 24-27 . X I .2002,2$ macho, varredura, 1 macho, armadilha Malaise, 1 macho, armadilha Möricke, C.O. Azevedo e eq. col. (MZSP, UFES); Santa Maria de Jetibá, 1 macho, Fazenda Paulo Seick, $20^{\circ} 02^{\prime} 31,1^{\prime \prime S} 40^{\circ} 41^{\prime} 51.3^{\prime \prime W}$, 06-13.XII.2002, armadilha Malaise, MT Tavares, C.O. Azevedo e eq. col. (UFES); 1 macho, Fazenda Clarindo Kruguer, 2004'27,9"S 4044'51.3"W, 29.XI-06.XII.2002, armadilha Malaise, M.T. Tavares, C.O. Azevedo e eq. col. (UFES); Santa Teresa, Estação Biol. Sta. Lucia, 1958’33,3"S 40³2’22,5"W, 1 macho, $19^{\circ} 58^{\prime} 25,2^{\prime \prime} \mathrm{S} 40^{\circ} 31^{\prime} 44,6^{\prime \prime} \mathrm{W}, 1$ macho, varredura, armadilha Malaise, 06-11.IV.2001, C.O. Azevedo e eq. col. (MZSP). Este material foi comparado a seis parátipos, todos de Santa Teresa, Espírito Santo, Brasil (UFES).

\section{Apenesia clypeata Leal \& Azevedo, 2001}

Esta espécie era conhecida apenas para o Paraná (Brasil), e é agora citada pela primeira vez para os Estados da Bahia, Espírito Santo, São Paulo e Santa Catarina. Nesta série, foram encontradas as seguintes variações: ápice do parâmero mais estreito; lobos ventrais do edeago fracamente angulosos. 
Material examinado. BRASIL, 1 macho, Bahia, Porto Seguro, Estação Ecol. Pau Brasil, $16^{\circ} 23^{\prime} 17,6^{\prime \prime}$ S 39¹0'55"W, 16.V.2002, varredura, C.O. Azevedo e eq. col. (MZSP); Espírito Santo, Santa Teresa, Estação Biol. Sta. Lucia, 1958'S 40³2’W, 06-12.IV.2001, 1 macho, varredura, 3 machos, armadilha Malaise, C.O. Azevedo e eq. col. (MZSP, UFES); São Paulo, Salesópolis, Estação Biol. Boracéia, 23³9’06,5"S 4553'48"W, 30.XI-5.IV.2001, 7 machos, armadilha Malaise, 4 machos, varredura, S.T.P. Amarante e eq. col. (MZSP, UFES); Ribeirão Grande, Parque Est. Intervales, $24^{\circ} 18^{\prime} 16^{\prime \prime S} 48^{\circ} 21^{\prime} 53^{\prime \prime} \mathrm{W}, 10-13 . X I i .2000,2$ machos, armadilha Malaise, 2 machos, varredura, M.T. Tavares e eq. col. (MZSP, UFES); 2 machos, Peruíbe, Estação Ecol. Juréia-Itatins, $24^{\circ} 31^{\prime} 06^{\prime \prime} \mathrm{S} 47^{\circ} 12^{\prime} 06^{\prime \prime} \mathrm{W}, 30 . \mathrm{IV}-5 . \mathrm{V} .2002$, varredura, N.W. Perioto e eq. col. (MZSP, UFES); 1 macho, Paraná, Morretes, Parque Est. do Pau Oco, 25³4’27,5"S 4853’33"W, 09.IV.2002, varredura, M.T. Tavares e eq. col. (MZSP); 1 macho, Santa Catarina, São Bento do Sul, CEPA-Rugendas, $26^{\circ} 19^{\prime} 25,6^{\prime \prime} \mathrm{S} \quad 49^{\circ} 18^{\prime} 26,5^{\prime \prime} \mathrm{W}$, 13-16.x.2001, armadilha Malaise, Penteado-Dias e eq. col. (MZSP).

\section{Apenesia perlonga sp. nov.}

(Fig. 7-9)

Diagnose. Castanho escuro, quase preto. Mandíbulas com um dente. Clípeo com lobo mediano arredondado. Fronte polida. Vértice quase reto. Disco pronotal sem carena transversal anterior. Metassomo sem pecíolo. Genitália com parâmeros alongados com superfície helicoidal; ramo ventral do dígito muito alongado, direcionando-se para o dorso; edeago uniformemente largo, com um par de lobos apicais arredondados, voltados para a região dorsal.

Descrição, macho: comprimento 4,68 mm; LFW 3,43 mm. Corpo castanho-escuro, quase preto, exceto propódeo, preto; mandíbula, antena, tégula e pernas castanhas; palpos castanho-claros; asas hialinas.

Cabeça (Fig. 7): mandíbula com um dente (Fig. 8). Clípeo com lobo mediano amplamente arredondado, com um dente mediano, carena mediana conspícua e completa. Primeiros quatro segmentos antenais na razão de 23:07:08:09, segmento III 1,6x mais longo que largo, segmento XI 1,4x mais longo que largo, pubescência flagelar subapressa, seu comprimento um terço da largura do segmento. Olhos pilosos. Fronte polida, com pontuação pequena. WH/LH 1,12; WF/WH 1,62; WF/HE 1,62; OOL/WOT 1,17; ângulo frontal do triângulo ocelar agudo; distância do topo do ocelo posterior à crista do vértice $0,57 \mathrm{x}$ DAO. Vértice quase reto, cantos arredondados. VOL/HE 0,54.

Mesossomo (Fig. 7): pronoto polido, muito piloso; carena transversal anterior ausente; notáulices completas. Disco propodeal 1,38x mais largo que longo, carena mediana ocupando a metade anterior do disco, carena transversal posterior ausente, área posterior polida grande, lados do propódeo e declividade areolado-rugosos. Mesopleura fracamente coriácea, calo pouco desenvolvido.

Metassomo: séssil. Genitália (Fig. 9): parâmeros alongados com superfície helicoidal, densamente piloso; volsela com ramo ventral do dígito muito alongado, passando sobre o dígito e a cúspide e direcionando-se para o dorso; cúspide projetada para o dorso, losangular em vista lateral; edeago uniformemente largo, mais alto do que a metade da altura do parâmero, um par de lobos apicais arredondados, voltados para a região dorsal.
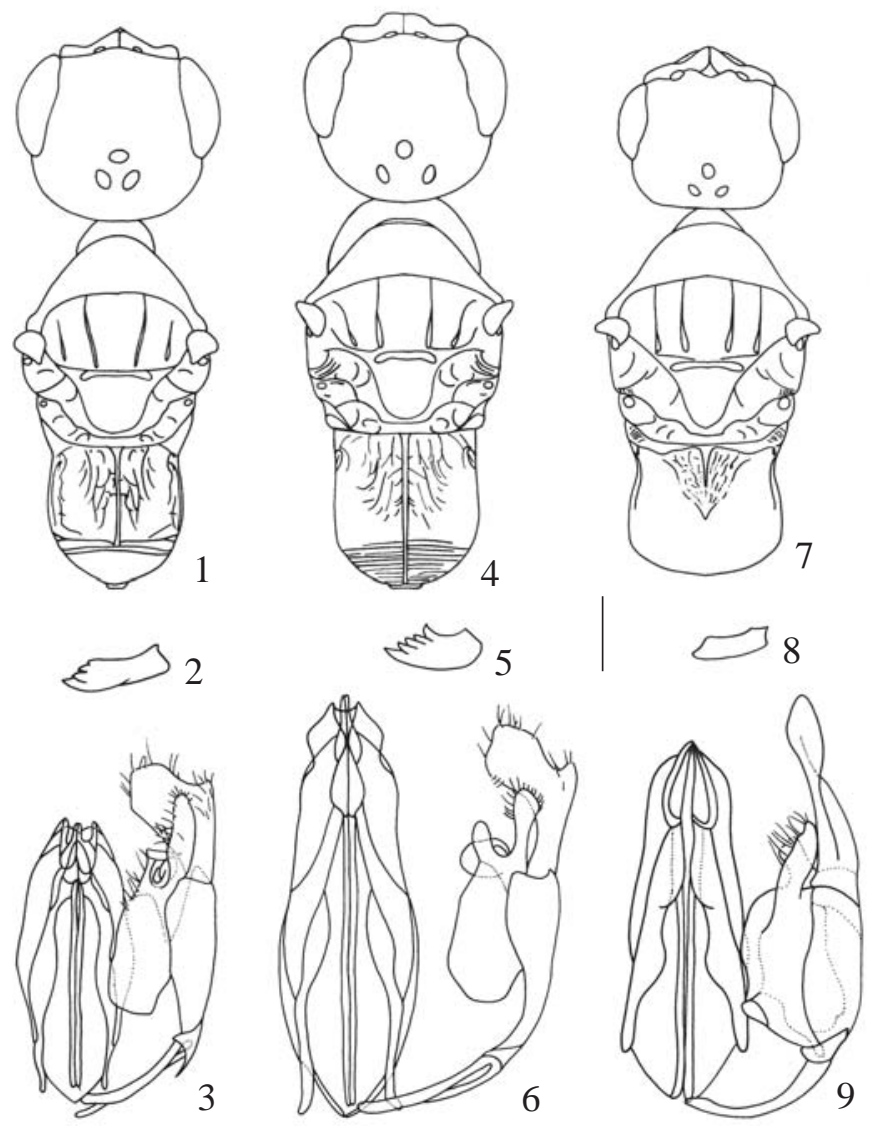

Figs. 1-9. 1-3, Apenesia pectinata sp. nov.: 1, holótipo macho, cabeça e mesossomo, dorsal; 2, mandíbula; 3, genitália, ventral; 4-6, Apenesia atlantica sp. nov.: 4, holótipo macho, cabeça e mesossomo, dorsal; 5, mandíbula; 6, genitália, ventral; 7-9, Apenesia perlonga sp. nov.: 7, holótipo macho, cabeça e mesossomo, dorsal; 8, mandíbula; 9, genitália, ventral. (Figs. 1, 2, 4, 5, 7, $8=0$ 0,5 mm; Figs. 3, 6, $9=155 \mathrm{~mm}$ ).

Material examinado. Holótipo macho, BRASIL, Espírito Santo, Atílio Vivacqua, Fazenda José Carlos Lustroza, 2055'57,6"S 41¹1'22.1"W, 13-20.II.2003, armadilha Malaise, M.T. Tavares, C.O. Azevedo e eq. col. (UFES). Parátipo: BRASIL, 1 macho, Espírito Santo, Pancas, Fazenda Juliberto Stur, $19^{\circ} 13^{\prime} 10,5^{\prime \prime} \mathrm{S} 40^{\circ} 46^{\prime} 23,8^{\prime \prime} \mathrm{W}, 24-31 . I .2003$, armadilha Malaise, M.T. Tavares, C.O. Azevedo e eq. col. (UFES).

Observações. Esta espécie se diferencia das outras do seu grupo por apresentar a mandíbula com apenas um dente e parâmero muito alongado (Fig. 9), enquanto as demais apresentam mandíbulas com cinco dentes e parâmero não tão alongado.

Etimologia. Refere-se ao tamanho do ramo ventral do dígito, muito longo.

Distribuição. Brasil (Espírito Santo).

\section{Apenesia exigua sp. nov. (Figs. 10-12)}

Diagnose. Preto. Mandíbulas com cinco dentes. Clípeo com lobo mediano arredondado. Fronte polida. Vértice amplamente arredondado. Disco pronotal com estrias transversais, sem carena transversal anterior. Metassomo peciolado. Genitália 
com porção apical do parâmero subretangular; ramo ventral do dígito curto, arredondado; edeago uniformemente largo, com um par de lobos externos largos e curtos, com um par filamentos internos.

Descrição, macho: comprimento 4,7 mm; LFW 3,32 mm. Cabeça e mesossomo pretos; metassomo castanho-escuro; mandíbula e antena castanhas; palpos, tégulas e pernas castanho-claras; asas hialinas.

Cabeça (Fig. 10): mandíbula com cinco dentes, o basal pontiagudo (Fig. 11). Clípeo com lobo mediano arredondado, com carena mediana alta e arqueada vista de perfil. Primeiros quatro segmentos antenais na razão de 5:1:4:4, segmento III $3 x$ mais longo que largo, segmento XI 5x mais longo que largo, pubescência flagelar subereta, seu comprimento menor que a largura do segmento. Olhos fracamente pilosos. Fronte polida, fortemente pontuada. WH/LH 0,93; WF/WH 0,64; WF/HE 1,06; OOL/WOT 1,23; ângulo frontal do triângulo ocelar agudo; distância do topo do ocelo posterior à crista do vértice $1,2 \mathrm{x}$ DAO. Vértice amplamente arredondado. VOL/HE 0,57.

Mesossomo (Fig. 10): pronoto com estrias transversais, pontuado; carena transversal anterior ausente, com depressão transversal acompanhando a margem posterior do disco; notáulices quase atingindo a margem anterior do mesoscuto. Disco propodeal 1,08x mais largo do que longo, carena mediana indefinida, carena transversal posterior presente, área lateroposterior, declividade e lados do propódeo estrigulosos. Mesopleura com calo fracamente coriáceo, bem desenvolvido.

Metassomo: peciolado. Genitália (Fig. 12): parâmero com base estreita, metade da altura do parâmero e menor do que a metade da largura do ápice, ápice subretangular e inclinado, fracamente piloso, cantos arredondados, margens retas; volsela com ramo ventral do dígito curto, ápice arredondado e piloso, menor do que um terço da altura da base do parâmero; basivolsela sem pêlos; edeago uniformemente largo, tão alto quanto a margem basal do ápice do parâmero, com um par de lobos externos largos e curtos, com um par filamentos internos.

Material examinado. Holótipo macho, BRASIL, Espírito Santo, Santa Teresa, Estação Biol. Sta. Lucia, 1958’21,1"S 40³2’05,5"W, 07.IV.2001, varredura, C.O. Azevedo e eq. col. (MZSP).

Observações. Esta espécie é descrita a partir de um único exemplar, e difere das outras deste grupo por apresentar edeago pouco desenvolvido e cúspide muito pequena, menor do que em A. pallidula Evans, 1963, e por possuir apenas um par de lobos apicais, muito longos.

Etimologia. Refere-se ao tamanho do ramo ventral do dígito, muito curto.

Distribuição. Brasil (Espírito Santo).

\section{Apenesia crenulata (Kieffer, 1910)}

(Figs. 13-15)

Esta espécie era conhecida para o Brasil (Amazonas, Pará, Espírito Santo e Santa Catarina) e Argentina. Era conhecida a partir da descrição da morfologia externa de um único exemplar. Neste estudo, seguem sua diagnose e a descrição detalhada da genitália. Nesta série, as variações encontradas foram:
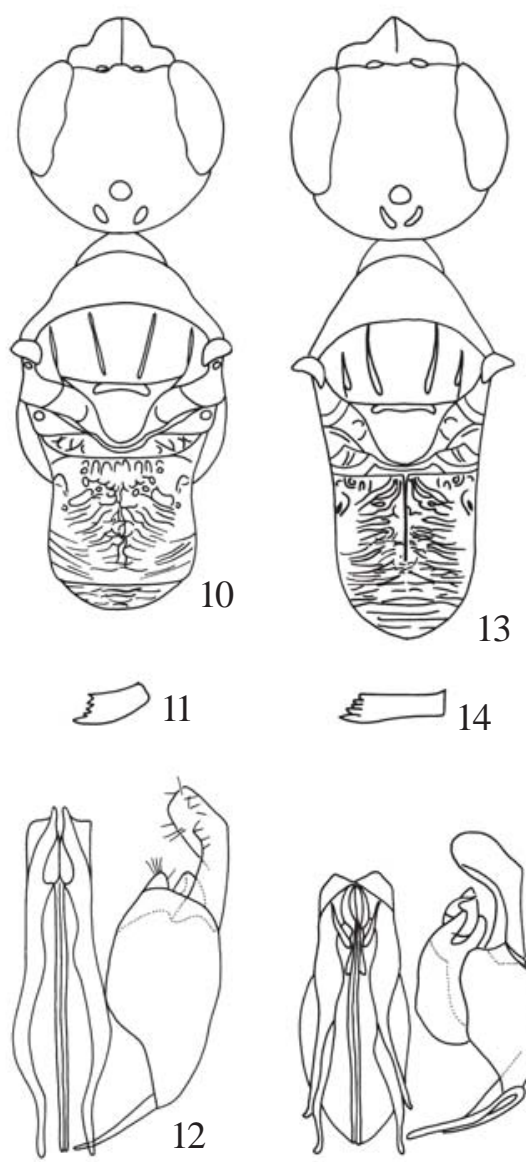
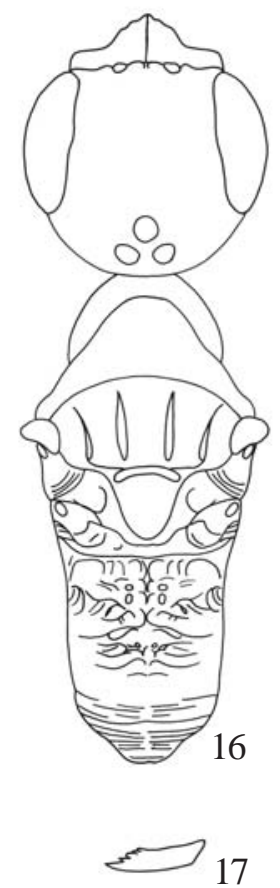

Figs. 10-17. 10-12, Apenesia exigua sp. nov.: 10, holótipo macho, cabeça e mesossomo, dorsal; 11, mandíbula; 12, genitália, ventral; 13-15, Apenesia crenulata: 13, macho, cabeça e mesossomo, dorsal; 14, mandíbula; 15, genitália, ventral; 16-17, Apenesia patens sp. nov.: 16, holótipo macho, cabeça e mesossomo, dorsal; 17, mandíbula. (Figs. 10, $11,13,14=0,5 \mathrm{~mm}$; Figs. 12, $15=155 \mathrm{~mm}$; Figs. 16, $17=0,32 \mathrm{~mm}$ ).

antenas totalmente castanhas; pontuação mais forte; notáulices completas ou incompletas somente na porção anterior. Este material foi comparado com o holótipo do (CASC).

Diagnose. Preto. Mandíbulas com cinco dentes (Fig. 14). Clípeo com lobo mediano angulado. Fronte polida. Vértice arredondado, levemente invaginado medianamente. Disco pronotal sem carena transversal anterior (Fig. 13). Metassomo peciolado.

Genitália (Fig. 15): parâmero com base larga, cerca da metade da largura do ápice do parâmero, ápice subretangular e inclinado, cantos arredondados, margem interna amplamente arredondada; volsela com ramo ventral do dígito com ápice arredondado, fracamente piloso, menor do que metade da altura da base do parâmero; cúspide grande, mais longa do que a metade do parâmero, triangular em vista ventral; basivolsela sem pêlos; edeago uniformemente largo, tão alto quanto a margem basal do ápice do parâmero, com um par de lobos laterais dilatados e arredondados. 
Material examinado. Holótipo macho, BRASIL, Espírito Santo, Santa Teresa, Estação Biol. Sta. Lucia, 1958’22,5"S 40³1’44,6"W, 07.IV.2001, varredura, C.O. Azevedo e eq. col. (MZSP). Parátipos: BRASIL, Espírito Santo, Santa Maria de Jetibá, 1 macho, Fazenda Clarindo Kruguer, $20^{\circ} 04^{\prime} 27,9^{\prime \prime} \mathrm{S} 40^{\circ} 44^{\prime} 51,3$ "W, 29.XI-06.XII.2002, armadilha Malaise, M.T. Tavares, C.O. Azevedo e eq. col. (UFES); 3 machos, Santa Teresa, mesmos dados do holótipo (MZSP, UFES).

\section{Apenesia patens sp. nov.}

(Figs. 16-18)

Diagnose. Preto. Mandíbulas com cinco dentes. Clípeo com lobo mediano angulado, fracamente crenulado. Fronte polida. Vértice amplamente arredondado. Disco pronotal com carena transversal anterior. Metassomo peciolado. Genitália com parâmeros subretangular; ramo ventral do dígito arredondado, cerca de metade da altura do parâmero; edeago uniformemente largo, com um par de lobos apicais largos e côncavos.

Descrição, macho: comprimento 4,23 mm; LFW 2,1 mm. Cabeça e mesossomo pretos; metassomo castanho-escuro; mandíbula e antena castanhas, exceto escapo, mais escuro; palpos, tégulas e pernas castanho-claros; asas hialinas.

Cabeça (Fig. 16): mandíbula com cinco dentes, o basal maior (Fig. 17). Clípeo com lobo mediano angulado, fracamente crenulado, com carena mediana muito alta e arqueada vista de perfil. Primeiros quatro segmentos antenais na razão de 13:03:14:12, segmento III 4,67x mais longo que largo, segmento XI 5,5x mais longo que largo; pubescência flagelar subereta, tão longa quanto a largura do segmento. Olhos glabros. Fronte polida, pontuações pequenas e distintas. WH/LH 0,93; WF/ WH 0,58; WF/HE 0,92; OOL/WOT 1; ângulo frontal do triângulo ocelar agudo; distância do topo do ocelo posterior à crista do vértice $0,5 \mathrm{x}$ DAO. Vértice amplamente arredondado. VOL/HE0,46.

Mesossomo (Fig. 16): pronoto polido, carena transversal anterior ausente, com depressão transversal acompanhando a margem posterior do disco; notáulices incompletas anteriormente. Disco propodeal tão longo quanto largo, carena mediana incompleta, carena transversal posterior indefinida, lados do propódeo polido, declividade finamente estrigulosa. Mesopleura polida, calo bem desenvolvido.

Metassomo: peciolado. Genitália (Fig. 18): parâmero com base estreita, cerca de um terço da largura do ápice do parâmero, ápice subretangular, pouco piloso, cantos arredondados, margem apical côncava, margem interna arredondada; volsela com ramo ventral do dígito piloso apicalmente, ápice arredondado, cerca de metade da altura do parâmero; basivolsela pilosa na metade superior; edeago uniformemente largo, tão alto quanto a margem basal do ápice do parâmero, ápice amplo, um par de lobos apicais largos e côncavos.

Material examinado. Holótipo macho, BRASIL, Alagoas, Quebrangulo, Reserva Biol. Pedra Talhada, 09¹4'54"S 36²5’32"W, 08-11.IX.2002, armadilha Malaise, Penteado-Dias e eq. col. (MZSP). Parátipos: BRASIL, 2 machos, Alagoas, mesmos dados do holótipo, exceto 11-14.IX.2002. (MZSP, UFES); 1 macho, Sergipe, Sta. Luzia do Itanhy, Crasto, $11^{\circ} 22^{\prime} 37,4^{\prime \prime S} 37^{\circ} 24^{\prime} 50,3 \mathrm{~W}, 31$.VII.2001, varredura, M.T. Tavares e eq. col. (MZSP); 1 macho, Bahia, Sapiranga, Reserva
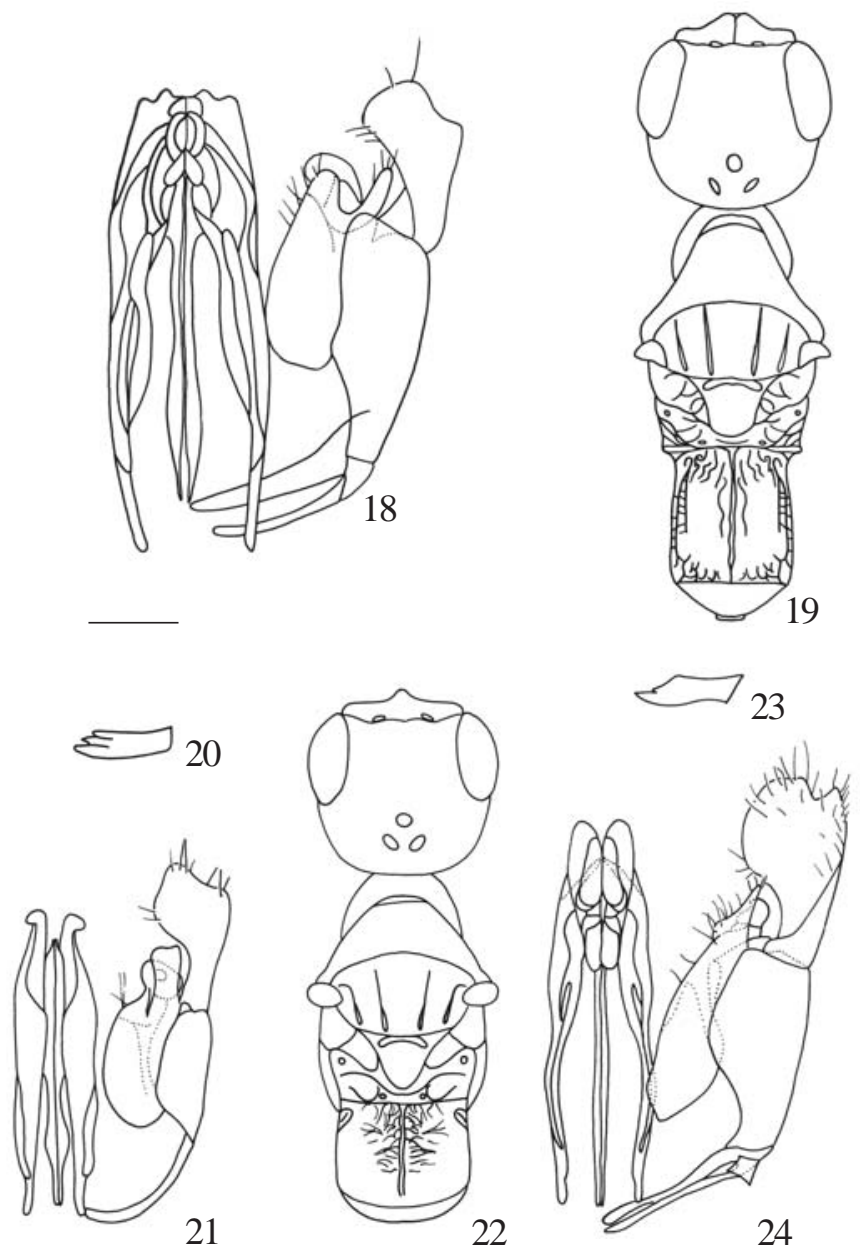

Figs. 18-24. 18, Apenesia patens sp. nov.: genitália, ventral; 19-21, Apenesia simplex sp. nov.: 19, holótipo macho, cabeça e mesossomo, dorsal; 20, mandíbula; 21, genitália, ventral; 22-24, Apenesia hepatica sp. nov.: 22, holótipo macho, cabeça e mesossomo, dorsal; 23, mandíbula; 24, genitália, ventral. (Figs. 18, $14=77$ mm; Figs. 19, 20, 22, $23=0,5$ $\mathrm{mm}$; Figs. $21=155 \mathrm{~mm}$ ).

de Sapiranga, $12^{\circ} 33^{\prime} 36,4^{\prime \prime} \mathrm{S} 38^{\circ} 02^{\prime} 57,2^{\prime \prime} \mathrm{W}, 19-22$.VII.2001, armadilha Malaise, M.T. Tavares e eq. col. (MZSP).

Observações. Esta espécie difere das outras do grupo por apresentar porte pequeno e o par de lobos apicais do edeago largos, enquanto as outras espécies apresentam o par de lobos afilados.

Etimologia. Refere-se ao fato dos lobos apicais do edeago serem largos.

Distribuição. Brasil (Alagoas, Sergipe, Bahia).

\section{grupo de espécies mexicana}

O grupo mexicana foi definido por Evans (1963) como aquelas espécies que possuem pronoto com carena transversal forte; metassomo não peciolado; parâmeros amplamente expandidos; e como as únicas espécies a possuir uma fóvea atrás da margem posterior do disco pronotal. 


\section{Apenesia concavata Corrêa \& Azevedo, 2001}

Esta espécie era conhecida para o Brasil (Espírito Santo), e agora é citada pela primeira vez para Sergipe, Bahia, Rio de Janeiro, São Paulo, Paraná e Santa Catarina. Nesta série, as variações encontradas foram: canto superior do parâmero mais alto do que na série tipo; edeago ultrapassando a altura da cúspide.

Material examinado. BRASIL, 1 macho, Sergipe, Sta. Luzia do Itanhy, Crasto, $11^{\circ} 22^{\prime} 37,4^{\prime \prime S} 37^{\circ} 24^{\prime} 50,3 \mathrm{~W}, 31$.VII.2001, varredura, M.T. Tavares e eq. col. (MZSP); Bahia, Porto Seguro, Estação Ecol. Pau Brasil, $16^{\circ} 23^{\prime} 17,6^{\prime \prime} \mathrm{S} 39^{\circ} 10^{\prime} 55^{\prime \prime} \mathrm{W}, 16-20 . \mathrm{V} .2002,3$ machos, varredura, 1 macho, armadilha Malaise, C.O. Azevedo e eq. col. (MZSP, UFES); Espírito Santo, 1 macho, Pancas, Faz. Juliberto Stur, $19^{\circ} 13^{\prime} 10,5^{\prime \prime} \mathrm{S} 40^{\circ} 46^{\prime} 23,8^{\prime \prime} \mathrm{W}, 31 . \mathrm{I}-07 . I I .2003$, armadilha Malaise, M.T. Tavares, C.O. Azevedo e eq. col. (UFES); Santa Teresa, Estação Biol. Sta. Lucia, $19^{\circ} 58^{\prime} \mathrm{S} 40^{\circ} 32^{\prime} \mathrm{W}, 07-11 . I V .2001,9$ machos, varredura, 1958'S 40³1'W, 07-11.IV.2001, 44 machos, varredura, 1 macho, armadilha Malaise, 1 macho, armadilha Möricke, C.O. Azevedo e eq. col. (MZSP, UFES); 1 macho, Santa Maria de Jetibá, Faz. Paulo Seick, $20^{\circ} 02^{\prime} 31,1^{\prime \prime} \mathrm{S} 40^{\circ} 41^{\prime} 51,3 \mathrm{lW}, 29 . X I-06 . X I I .2002$, armadilha Malaise, M.T. Tavares, C.O. Azevedo e eq. col. (UFES); 16 machos, Vitória, Parque Est. Fonte Grande, $20^{\circ} 17^{\prime} 51,7^{\prime \prime S} 40^{\circ} 20^{\prime} 13,1$ "W, 11.VII.200030.VI.2001, varredura, Azevedo, Kawada e Santos col. (UFES); 1 macho, Domingos Martins, Parque Est. Pedra Azul, 20²5'55"S 41 00 '53"W, 26.VII-02.IX.2003, armadilha Malaise, C.O. Azevedo e eq. col (UFES); 1 macho, Alegre, Pq. E. Cachoeira da Fumaça, 11-12.X.2000, varredura, Azevedo \& Santos col. (UFES); 4 machos, Rio de Janeiro, Santa Maria Madalena, Parque Est. de Desengano, 21 ${ }^{\circ} 59^{\prime} 03^{\prime \prime S} 41^{\circ} 57^{\prime} 08^{\prime \prime W}, 16-$ 22.IV.2002, armadilha Malaise, A.M. Penteado-Dias e eq. col. (MZSP, UFES); São Paulo, 3 machos, Salesópolis, Estação Biol. Boracéia,

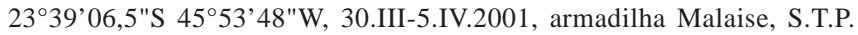
Amarante e eq. col. (MZSP); 2 machos, Ribeirão Grande, Parque Estadual de Intervales, $24^{\circ} 17^{\prime} 34^{\prime \prime S} 48^{\circ} 22^{\prime} 03^{\prime \prime W}, 12$.XII.2000, varredura, M.T. Tavares e eq. col. (MZSP, UFES); Paraná, Morretes, Parque Est. do

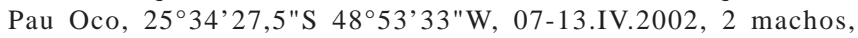
varredura, 8 machos, armadilha Malaise, M.T. Tavares e eq. col. (MZSP, UFES); Santa Catarina, São Bento do Sul, CEPA-Rugendas, $26^{\circ} 19^{\prime} 25,6^{\prime \prime S} 49^{\circ} 18^{\prime} 26,5^{\prime \prime} \mathrm{W}, 16-19 . X .2001,2$ machos, armadilha Malaise, 1 macho, varredura, Penteado-Dias e eq. col. (MZSP, UFES).

\section{Apenesia distincta Corrêa \& Azevedo, 2001}

Esta espécie era conhecida para o Espírito Santo e Paraná (Brasil). É aqui citada pela primeira vez para Alagoas, Sergipe, Rio de Janeiro e São Paulo. Nesta série são encontradas algumas variações: lobo mediano do clípeo arredondado, genitália com parâmero mais estreito, edeago alcançando a metade da altura do parâmero, projeções filamentosas maiores que no holótipo e ramo ventral do dígito menor em alguns exemplares de Alagoas e do Espírito Santo (Santa Teresa e Santa Maria de Jetibá).

Material examinado. BRASIL, 5 machos, Alagoas, Quebrangulo, Reserva Biol. Pedra Talhada, 09¹4'54"S 36²5'32"W, 0814.IX.2002, armadilha Malaise, Penteado-Dias e eq. col. (MZSP); 1 macho, Sergipe, Sta. Luzia do Itanhy, Crasto, $11^{\circ} 22^{\prime} 37,4^{\prime \prime} \mathrm{S}$ $37^{\circ} 24^{\prime} 50,3 \mathrm{~W}, 31$.VII.2001, varredura, M.T. Tavares e eq. col. (MZSP); Espírito Santo, Sooretama, Reserva Biol. Sooretama, $19^{\circ} 00^{\prime} 11,5^{\prime \prime S} 40^{\circ} 07^{\prime} 08^{\prime \prime} \mathrm{W}, 21-24 . \mathrm{III} .2002,1$ macho, varredura, 1 macho, armadilha Malaise, C.O. Azevedo e eq. col. (MZSP); Santa Teresa, Estação Biol. Sta. Lucia, 1958'S 40³2'W, 06-12.IV.2001, 5 machos, varredura, 4 machos, armadilha Malaise, $19^{\circ} 58^{\prime} \mathrm{S} 40^{\circ} 31^{\prime} \mathrm{W}$,

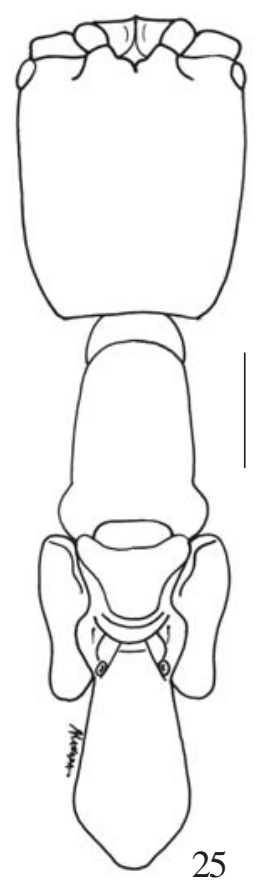

Fig. 25. Apenesia elongata: fêmea, cabeça e mesossomo, dorsal (escala $=0,5 \mathrm{~mm}$ ).

07-11.IV.2001, 4 machos, varredura, C.O. Azevedo e eq. col. (MZSP, UFES); Santa Maria de Jetibá, 1 macho, Fazenda Paulo Seick, $20^{\circ} 02^{\prime} 31,1^{\prime \prime} \mathrm{S} 40^{\circ} 41^{\prime} 51,3 \mathrm{~W} \mathrm{~W}, 29$.XI-06.XII.2002, armadilha Malaise, M.T. Tavares, C.O. Azevedo e eq. col. (UFES); 3 machos, Fazenda Clarindo Kruguer, $20^{\circ} 04^{\prime} 27,9^{\prime \prime} \mathrm{S} 40^{\circ} 44^{\prime} 51,3$ "W, 29.XI-13.XII.2002, armadilha Malaise, M.T. Tavares, C.O. Azevedo e eq. col. (UFES); 1 macho, Domingos Martins, Parque Est. Pedra Azul, 20²5'55"S $41^{\circ} 00$ '53"W, 26.VII-02.IX.2003, armadilha Malaise, C.O. Azevedo e eq. col (UFES); 2 machos, Alegre, Pq. E. Cachoeira da Fumaça, 1315.X.2000, varredura, Azevedo \& Santos col. (UFES); Rio de Janeiro, 2 machos, Santa Maria Madalena, Parque Est. de Desengano,

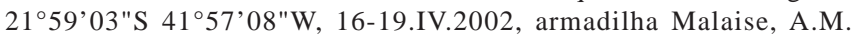
Penteado-Dias e eq. col. (MZSP, UFES); São Paulo, Ubatuba, Parque

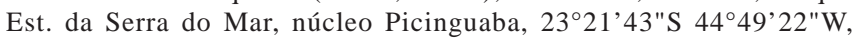
21-27.I.2002, 3 machos, armadilha Malaise, 3 machos, varredura, N.W. Perioto e eq. col. (MZSP, UFES); 2 machos, Salesópolis, Estação Biol. Boracéia, $23^{\circ} 39^{\prime} 06,5^{\prime \prime} S$ 455' 48"W, 4-5.IV.2001, varredura, S.T.P Amarante e eq. col. (MZSP, UFES); 1 macho, Ribeirão Grande, Parque Estadual de Intervales, 241' $16^{\prime \prime S} 48^{\circ} 21^{\prime} 53^{\prime \prime W}, 10-$ 13.XII.2000, armadilha Malaise, M.T. Tavares e eq. col. (MZSP); Peruíbe, Estação Ecol. Juréia-Itatins, 2431'06"S 47¹2’06"W, 56.V.2002, 2 machos, varredura, 1 macho, armadilha Malaise, N.W. Perioto e eq. col. (MZSP, UFES).

\section{Apenesia inca Evans, 1963}

Esta espécie era conhecida para o Peru, Equador e Brasil (Santa Catarina). É agora citada pela primeira vez para o estado de São Paulo (Brasil). Nesta série, foram encontradas as seguintes variações: fronte mais coriácea e clípeo mais escuro do que os espécimes da série tipo. Este material foi comparado a um exemplar de Tucumán, Argentina (UFES).

Material examinado. BRASIL, 2 machos, São Paulo, Ubatuba, Parque Est. da Serra do Mar, Núcleo Picinguaba, 2321'43"S 4449'22"W, 21-24.I.2004, armadilha Malaise, N.W. Perioto e eq. col. (MZSP, UFES). 


\section{Apenesia neotropica (Kieffer, 1910)}

Esta espécie era conhecida para o Brasil (Pará) e para o Peru, e agora é citada pela primeira vez para Linhares (Brasil, Espírito Santo).

Material examinado. BRASIL, Espírito Santo, Linhares, 5 machos, Faz. Maria Bonita, Mata cabruca, 11-13.VIII.2000, 4 machos, Res. Biol. Goytacazes, Mata de aluvião, 6-8.X.2000, varredura, Azevedo \& Schiffler col. (UFES). Este material foi comparado com o holótipo do Brasil, Pará (CASC).

\section{Apenesia simplex sp. nov.}

(Figs. 19-21)

Diagnose. Preto. Mandíbulas com três dentes. Clípeo com lobo mediano bidentado. Fronte coriácea. Vértice amplamente arredondado. Disco pronotal com carena transversal anterior. Tíbia mediana subespinhosa. Metassomo sem pecíolo. Genitália com parâmero subretangular; ramo ventral do dígito dilatado, ápice côncavo; edeago mais largo no ápice, laminar, superfície ventral côncava, ápice arredondado em vista lateral.

Descrição, macho: comprimento 5,55 mm; LFW 3,43 mm. Cabeça e mesossomo pretos; metassomo castanho-escuro; mandíbula castanha; antenas, palpos, tégulas e pernas castanho-claras; asas hialinas.

Cabeça (Fig. 19): mandíbula com três dentes (Fig. 20). Clípeo com lobo mediano bidentado. Primeiros quatro segmentos antenais na razão de 16:04:09:07, segmento III 3x mais longo que largo, segmento XI 2x mais longo que largo, pubescência flagelar subereta, seu comprimento menor que a metade da largura do segmento. Olhos fracamente pilosos. Fronte coriácea, fortemente pontuada. WH/LH 0,95; WF/WH 0,62; WF/HE 1,2; OOL/WOT 1,2; ângulo frontal do triângulo ocelar agudo; distância do topo do ocelo posterior à crista do vértice $1,33 x$ DAO. Vértice amplamente arredondado. VOL/HE 0,69 .

Mesossomo (Fig. 19): pronoto coriáceo, fortemente pontuado, carena transversal anterior forte; notáulices completas. Disco propodeal 1,1x mais longo que largo, carena mediana completa, fraca posteriormente, carena transversal posterior presente, lados do disco pronotal coriáceos, lados do propódeo estriados, declividade polida no centro e grosseiramente areolada na periferia, sem carena mediana. Mesopleura coriácea, calo bem desenvolvido. Tíbia mediana subespinhosa.

Metassomo: séssil. Genitália (Fig. 21): parâmero com base estreita, cerca de um terço do comprimento do parâmero, ápice subretangular, cantos arredondados, margem apical côncava e pilosa, margem interna reta, margem basal com dois pêlos curtos; volsela com ramo ventral do dígito dilatado, ápice côncavo, menor do que a metade da altura do parâmero; basivolsela com cerca de três pêlos longos próximos à base do dígito; edeago mais largo no ápice, laminar, superfície ventral côncava, ápice arredondado em vista lateral, menor do que a metade da altura do parâmero.
Material examinado. Holótipo macho, BRASIL, Espírito Santo, Santa Teresa, Estação Biol. Sta. Lucia, 1958'25"S 40³1'44,6"W, 08.IV.2001, varredura, C.O. Azevedo e eq. col. (MZSP). Parátipo: BRASIL, 2 machos, Espírito Santo, mesmos dados do holótipo (MZSP).

Observações. Esta espécie é semelhante a A. inca Evans, 1963 por apresentar parâmero subquadrado e ápice do ramo ventral do dígito amplamente arredondado, porém A. simplex apresenta a porção apical do parâmero subretangular e ápice do ramo ventral do dígito côncavo, enquanto $A$. inca apresenta porção apical do parâmero quadrada e ápice do ramo ventral do dígito convexo.

Etimologia. Refere-se ao fato da genitália ser pouco complexa em relação às outras espécies do grupo.

Distribuição. Brasil (Espírito Santo).

\section{grupo de espécies nitida}

As espécies do grupo nitida foram definidas por (Evans, 1963) como aquelas com mandíbula com os dentes apicais fundidos em uma lâmina, e somente com o dente apical distinto; clípeo curto e obtusamente angulado, com ápice simples ou bidentado; metassomo peciolado; parâmeros amplamente expandidos; e edeago terminando em quatro lobos estreitos.

\section{Apenesia quadrata Evans, 1963}

Esta espécie conhecida para o Brasil (Minas Gerais). Esta é a primeira citação para o estado do Espírito Santo.

Material examinado. BRASIL, 1 macho, Espírito Santo, Santa Maria de Jetibá, Fazenda Paulo Seick, 2002'31,1"S 4041'51,3"W, 29.XI06.XII.2002, armadilha Malaise, M.T. Tavares, C.O. Azevedo e eq. col. (UFES).

\section{Apenesia hepatica sp. nov.}

(Figs. 22-24)

Diagnose. Preto. Mandíbulas com um único dente apical. Clípeo com lobo mediano subangulado. Fronte polida. Vértice reto, cantos amplamente arredondados. Disco pronotal com carena transversal anterior. Tíbia mediana subespinhosa. Metassomo com pecíolo longo. Genitália com parâmero amplo; ramo ventral do dígito dilatado, ápice truncado; edeago uniformemente largo, com um par de lobos laterais arredondados.

Descrição, macho: comprimento 5,18 mm; LFW 3,43 mm. Cabeça e mesossomo pretos; metassomo castanho; mandíbula castanha; antenas, palpos, tégulas e pernas castanho-claros; asas hialinas.

Cabeça (Fig. 22): mandíbula com apenas um dente apical (Fig. 23). Clípeo com lobo mediano subangulado, com as margens laterais côncavas, sem carena mediana. Primeiros quatro segmentos antenais na razão de 09:02:03:03, segmento III $3 \mathrm{x}$ mais longo que largo, segmento XI $4 \mathrm{x}$ mais longo que largo, pubescencia flagelar subereta, seu comprimento quase da largura do segmento. Olhos glabros. Fronte polida, 
pontuações muito pequenas e esparsas. WH/LH 1; WF/WH 0,6; WF/HE 1,29; OOL/WOT 1,33; ângulo frontal do triângulo ocelar agudo; distância do topo do ocelo posterior à crista do vértice $1,5 \mathrm{x}$ DAO. Vértice reto com cantos amplamente arredondados. VOL/HE 0,7 .

Mesossomo (Fig. 22): pronoto polido, pontuações esparsas; carena transversal anterior presente; notáulices incompletas anteriormente. Disco propodeal tão longo quanto largo, carena mediana incompleta, carena transversal posterior presente, área latero-posterior polida, declividade fracamente estrigulosa, lados do propódeo polidos à frente, muito fracamente coriáceo atrás. Mesopleura polida, pouco pilosa, calo bem desenvolvido. Tíbia mediana subespinhosa.

Metassomo: peciolado, pecíolo longo. Genitália (Fig. 24): parâmero com base estreita, menor do que um terço da altura do ápice do parâmero, ápice amplo, margem apical côncava e pilosa, cantos arredondados; volsela com ramo ventral do dígito dilatado, ápice truncado, densamente piloso na região ventral, tão longo quanto a margem basal do ápice do parâmero; basivolsela fracamente pilosa na metade superior; edeago uniformemente largo, maior do que a metade da altura do ápice do parâmero, um par de lobos laterais arredondados.

Material examinado. Holótipo macho, BRASIL, Bahia, Sapiranga, Reserva de Sapiranga, $12^{\circ} 33^{\prime} 58,5^{\prime \prime S} 38^{\circ} 02^{\prime} 57,2^{\prime \prime W}, 16-19$.VII.2001, armadilha Malaise, M.T. Tavares e eq. col. (MZSP). Parátipos: BRASIL, Sergipe, Sta. Luzia do Itanhy, Crasto, $11^{\circ} 22^{\prime} 37,4^{\prime \prime} S 37^{\circ} 24^{\prime} 50,3$ "W, 29-31.VII.2001, 4 machos, armadilha Malaise, 2 machos, varredura, M.T. Tavares e eq. col. (MZSP, UFES); 9 machos, Bahia, mesmos dados do holótipo, exceto $11^{\circ} 22^{\prime} 39,6^{\prime \prime S} 37^{\circ} 25^{\prime} 04,4^{\prime \prime} \mathrm{W}, 12^{\circ} 33^{\prime} \mathrm{S}$ $38^{\circ} 02^{\prime} \mathrm{W}, 12^{\circ} 33^{\prime} \mathrm{S} 38^{\circ} 03^{\prime} \mathrm{W}, 19-25$.VII.2001, varredura e armadilha Möricke (MZSP, UFES).

Variações. Antenas mais escuras apicalmente ou totalmente escuras; metassomo mais claro.

Observações. Esta espécie é semelhante à A. williamsi Evans, 1966, mas difere por apresentar apenas um par de lobos apicais no edeago.

Etimologia. Refere-se ao fato dos lobos apicais do edeago lembrarem lobos hepáticos.

Distribuição. Brasil (Sergipe, Bahia).

\section{grupo de espécies pilicornis}

Evans (1963) definiu o grupo pilicornis como aquelas espécies que possuem a pubescência flagelar curta e com cerdas eretas; disco pronotal sem carenas e relativamente alongado, lados côncavos; metassomo não peciolado; cúspide terminando em um processo fortemente separado do dígito, o último com dois braços fortemente associados; e parâmeros truncados e sem lobos.

\section{Apenesia elongata Evans, 1963}

(Fig. 25)

Esta espécie era conhecida para o Brasil (Rio de Janeiro, Santa Catarina), é citada pela primeira vez para os estados de Pernambuco, Bahia, Espírito Santo e São Paulo. Nesta série, são encontradas as seguintes variações em relação à série tipo: altura dos lobos membranosos do edeago tão longos quanto o ápice do parâmero, exceto nos exemplares da Bahia e no Paraná; forma dos lobos arredondada nos exemplares do Espírito Santo, São Paulo, Paraná e Santa Catarina. Além disto, foi encontrada pela primeira vez uma fêmea em cópula proveniente da Reserva Biológica de Duas Bocas, Espírito Santo, a qual é descrita abaixo.

Descrição, fêmea: comprimento $5,38 \mathrm{~mm}$. Corpo castanho-claro. Cabeça (Fig. 25): mandíbula com quatro dentes em uma série oblíqua. Clípeo com lobo mediano trapezoidal, carena mediana reta no perfil. Olhos circulares, com apenas uma faceta. Espaço malar muito reduzido, olho distante da base da mandíbula 0,33 X o seu diâmetro. Fronte polida, com linhas canaliculadas longitudinais, com pontuações densas, grandes e rasas. Cabeça subretangular, $1,14 \mathrm{x}$ mais longa que larga, vértice quase reto, um pouco côncavo. Largura máxima do disco propodeal 0,15 sua menor largura. Tíbia mediana pouco espinhosa. Metassomo sem pecíolo.

Observações. Duas característica da fêmea desta espécie chamam a atenção por serem pouco freqüentes no gênero: olhos com apenas um omatídeo e disco propodeal pouco constrito anteriormente, enquanto que as fêmeas da maioria das espécies apresentam olhos com mais do que cinco omatídeos e disco propodeal claramente constrito.

Material examinado. BRASIL, 4 machos, Pernambuco, Recife, Parque dos Dois Irmãos, 0800’37,7"S 3456’31"W, armadilha Malaise, 17-23.VII.2002, S.P.T. Amarante \& eq. col. (MZSP); Bahia, 1 macho, Ilhéus, Mata Esperança, 1446'S 39॰04'W, 15-18.V.2002, armadilha Malaise, A.M. Penteado-Dias e eq. col. (MZSP); 3 machos, Porto Seguro, Estação Ecol. Pau Brasil, 16²3'17,6"S 39¹0'55"W, 16.V.2002, varredura, C.O. Azevedo e eq. col. (MZSP, UFES); Espírito Santo, Pancas, Fazenda Juliberto Stur, 5 machos, $19^{\circ} 13^{\prime} 10,5^{\prime \prime S} 40^{\circ} 46^{\prime} 23,8^{\prime \prime} \mathrm{W}$, 3 machos, $19^{\circ} 12^{\prime} 54,8^{\prime \prime S} 40^{\circ} 47^{\prime} 52,5^{\prime \prime} \mathrm{W}, 24 . I-07 . I I .2003$, armadilha Malaise, M.T. Tavares, C.O. Azevedo e eq. col. (UFES); Santa Teresa, Estação Biol. Sta. Lucia, 1958'S 40³2'W, 06-12.IV.2001, 4 machos, varredura, 9 machos, armadilha Malaise, 1958'S 40³1'W, 07 10.IV.2001, 5 machos, varredura, C.O. Azevedo e eq. col. (MZSP, UFES); Santa Maria de Jetibá, 15 machos, Fazenda Paulo Seick, $20^{\circ} 02^{\prime} 31,1^{\prime \prime S ~} 40^{\circ} 41^{\prime} 51,3 " \mathrm{~W}, 29 . X I-13$.XII.2002, armadilha Malaise, M.T. Tavares, C.O. Azevedo e eq. col. (UFES); 13 machos, Fazenda Clarindo Kruguer, 2004'27,9"S 4044'51,3"W, 29.XI-13.XII.2002, armadilha Malaise, M.T. Tavares, C.O. Azevedo e eq. col. (UFES); 1 macho e 1 fêmea em cópula, Cariacica, Res. Biol. Duas Bocas, 19.XI.1987, armadilha Möricke, A.P. Aguiar col. (UFES); 2 machos, Domingos Martins, Parque Est. Pedra Azul, 20²5'55"S 4100'53"W, 26.VII-02.IX.2003, armadilha Malaise, C.O. Azevedo e eq. col (UFES); Rio de Janeiro, Santa Maria Madalena, Parque Est. de Desengano, 21 59'03"S 41 $57^{\circ}$ '08"W, 16-21.IV.2002, 1 macho, armadilha Malaise, 1 macho, varredura, A.M. Penteado-Dias e eq. col. (MZSP); 6 machos, Nova Iguaçu, Reserva Biol. de Tinguá, 2234'S 4326'W, 5-8.III.2002, armadilha Malaise, S.T.P. Amarante e eq. col. (MZSP, UFES); São Paulo, Salesópolis, Estação Biol. Boracéia, 2339'06,5"S 4553'48"W, 30.III5.IV.2001, 41 machos, armadilha Malaise, 1 macho, varredura, S.T.P. Amarante e eq. col. (MZSP, UFES); 25 machos, Ribeirão Grande, Parque

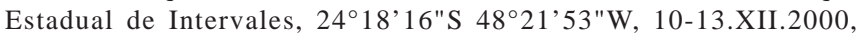
armadilha Malaise, M.T. Tavares e eq. col. (MZSP, UFES); Santa Catarina, São Bento do Sul, CEPA-Rugendas, 26¹9'25,6"S 49¹8'26.5"W, 1319.X.2001, 21 machos, armadilha Malaise, 6 machos, armadilha Möricke, Penteado-Dias e eq. col. (MZSP, UFES). 
Agradecimentos. Ao Laboratório de Genética (UFES) pelo empréstimo da câmara-clara usada para ilustração da genitália; ao BIOTA/ FAPESP, processo $\mathrm{n}^{\circ}$ 98/05083-0 e ao CNPq, processo . $^{\circ} 469321 / 00$ 8, pelo apoio financeiro; ao FACITEC/PMV, processo $n .^{\circ} 004 / 2000$, pelo apoio financeiro e pela concessão da bolsa de mestrado ao primeiro autor; ao $\mathrm{CNPq}$ pela bolsa de produtividade em pesquisa, processo $\mathrm{n}^{\circ} 303216 / 2004-2$.

\section{REFERÊNCIAS}

Corrêa, M. S. \& C. O. Azevedo. 2001. Taxonomia de Apenesia (Hymenoptera, Bethylidae) da Reserva Biológica de Duas Bocas, Espírito Santo, Brasil. Iheringia, série Zoologia 90: 167-174.

Evans, H. E. 1963. A revision of the Apenesia in the Americas
(Hymenoptera, Bethylidae). Bulletin of the Museum of Comparative Zoology 163: 249-359.

Harris, R. A. 1979. A glossary of surface sculpturing. Occasional Papers in Entomology 28: 1-31.

Leal, M. S. \& C. O. Azevedo. 2001. Taxonomy of Apenesia (Hymenoptera, Bethylidae) from Paraná, Brazil. Revista Brasileira de Zoologia 18: 673-679.

Ogloblin, A. A. 1930. Notes on Bethylidae with the description of two new species from Missiones. Revista de La Sociedad Entomologica Argentina 12: 15-27.

Waichert, C. \& C. O. Azevedo. 2002. Taxonomy of Apenesia (Hymenoptera, Bethylidae) from Estação Biológica de Santa Lúcia, Espírito Santo, Brazil. Iheringia, série Zoologia 93: 207-211. Westwood, J. O. 1874. Thesaurus Entomologicus Oxoniensis. Oxford, The Clarendon Press, xxiv $+205 p$ 